\title{
Walk and trot in the horse at driving: kinematic adaptation of its natural gaits
}

\author{
Francisco MiRó*, Joaquín VIVo, Rosario CANO, Andrés Diz, \\ Alfonso Martínez GALISTEO
}

\begin{abstract}
Department of Comparative Anatomy and Pathology, University of Córdoba, Campus Rabanales, Edif. Sanidad Animal, Cra Madrid-Cádiz Km. 396, 14071 Córdoba, Spain
\end{abstract}

(Received 22 July 2005 - Accepted 15 September 2006)

\begin{abstract}
The walk and trot at hand and at driving of five Andalusian Purebred stallions were studied by a 2D semiautomatic analysis system. Linear, temporal and angular variables from the right fore and hind limbs were obtained by using a 2D kinematic analysis system. In order to identify significant differences between handled and driving gaits, a paired Student $t$-test was performed. The swing period and the stride lengths of both fore and hind limbs and the overreach distance were lower at driving. Stride durations and Retraction-Protraction angle values in the hind limbs at trot did not differ under different conditions but scapular values at walk and trot, fore fetlock variables at trot and some of the stifle and tarsus parameters at walk and trot were modified by the use of the vehicle. It may be assumed that at fixed speeds driving horses try to maintain the stride duration of their natural gaits.
\end{abstract}

\section{horse / walk / trot / driving / kinematics}

Résumé - Le pas et le trot chez le cheval à l'attelage : adaptation cinématique des allures naturelles. Le pas et le trot à la main et à l'attelage de cinq étalons Andalous ont été étudiés à l'aide d'un système d'analyse semi-automatique du mouvement en 2 dimensions. Des variables linéaires, temporelles et d'angles des membres antérieur et postérieur droits ont été obtenues en utilisant la méthode cinématique en 2D. Afin d'identifier les différences significatives entre les allures à la main et les allures à l'attelage un test de Student apparié a été mis en oeuvre. La période de balancement et la longueur des foulées des membres antérieur et postérieur et la distance entre deux posers successifs des pieds avant et arrière (overreach distance) étaient inférieures lorsque les animaux étaient menés à l'attelage. La durée des foulées et les valeurs des angles de RétractionProtraction pour les membres postérieurs au trot n'ont pas différé dans ces conditions, en revanche, les valeurs obtenues pour les omoplates chez le cheval au pas et au trot, les variables du boulet au trot et certains paramètres du grasset et du tarse à la main et au trot ont été modifiés lors de l'utilisation de la voiture attelée. On peut supposer qu'à vitesse constante les chevaux à l'attelage essayent de maintenir la durée des foulées au niveau de celle de leurs allures naturelles.

\section{cheval / pas / trot / attelage / cinématique}

\footnotetext{
* Corresponding author: an1mirof@uco.es
} 


\section{INTRODUCTION}

According to Clayton [9], the various equestrian competitions have different requirements with regards to the gaits used and the manner in which they are performed. The selection process for sporting purposes has been mainly based on subjective criteria although studies of Grant [17], Back et al. [3,4], and Holmström et al. [21] have defined objective locomotion characteristics for performance prediction. Much has been written during the last two decades on basic stride characteristics, such as temporal, linear and angular variables, in different gaits and sport situations by Galisteo et al. $[14,15]$, Clayton $[9,10]$ and Miró et al. [23], and on coordination of joints within the equine fore and hind limbs by Back et al. [5, 6]. Concerning draught horses, studies on physiological adaptation to ploughing work by Perez et al. [24] and driving competitions by Snow [26] have been carried out. However, few data are available regarding the basic stride characteristics of driving horses. Gottlieb et al. [16] evaluated the circulatory and muscle metabolic responses in addition to stride length changes in horses which performed incremental draught work at a low trotting speed on a treadmill. In Combined Driving Events, the FEI (Fédération Équestre Internationale) regulates the competition rules and one of the three trials is the Driving Dressage test, in which judges evaluate the correctness of the horses' gaits.

The vehicle and rider's weight are supposed to change the natural kinematics by overloading the locomotion performance. A kinematic study carried out by Sloet et al. [25] analysed the changes in response to loading horses with a rider or an equivalent amount of dead weight, and they found an increase in the relative stance duration and small, but significant, differences in the fetlock extension and the maximal fetlock range of motion. Clayton [11] reported that an addition of $18 \mathrm{~kg}$ to the rider's weight increased the maximal extension of the fetlock and carpal joints in the leading fore limb in jumping horses during the landing phase. Linear and angular variables of horses with different abilities in performing collected gaits were analysed by Miró et al. [23]. Holmström et al. [22] described the biokinematic effects of collection in the elite dressage horse by means of studying angle patterns and hoof trajectories in collected trotting gaits and in the trot at hand as a reference. Cano et al. [8] and Back et al. [4] evaluated the effect of growth on biokinematic characteristics in Andalusian horses and Dutch Warmblood horses at trot, respectively, and Cano et al. [7] found kinematic differences between young and adult Andalusian horses at trot, pointing out that the increase in weight during growth or the difference in weight between young and adult horses may be the cause of some changes in locomotion.

The aim of the present study was to evaluate the adaptation in the kinematics of the horse from its natural walk and trot to driving conditions.

\section{MATERIALS AND METHODS}

Five Andalusian Purebred stallions $(9.6 \pm 2.8$ years old, $1.64 \pm 0.02 \mathrm{~m}$ height at withers) were used in this study. All the horses were included in the same training programme since they were participating in national and international driving competitions in the type Four-in-Hand (two horses in front as leaders and two behind as wheelers, drawing a 4-wheel vehicle, driven by the competitor with two grooms behind him). Self-adhesive markers (32 $\mathrm{mm}$ in diameter) were placed on the right side of the horses over easily identifiable anatomical references described previously by Cano et al. [7] and shown in Figure 1. Then, 1.2-m-height markers graduated at $0.1 \mathrm{~m}$ were placed every $2 \mathrm{~m}$ 


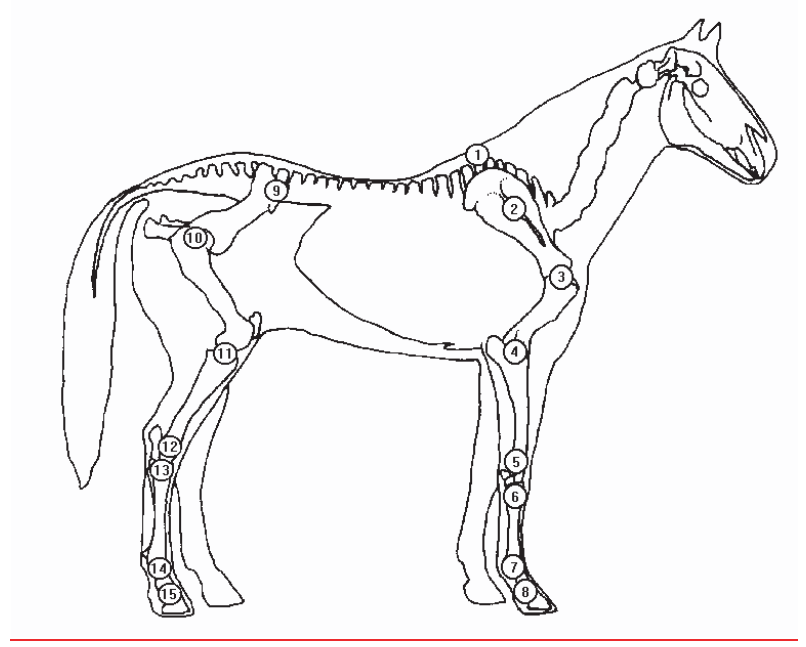

Figure 1. Schematic representation of the position of the markers. 1. Withers, 2. Tuber spina scapulae, 3. Tuberculum majus humerus (pars caudalis), 4. Ligament collaterale cubiti laterale, 5. Procesus styloideus lateralis radii, 6. Basis os IV metacarpale, 7. Ligament collaterale metacarpophalangi laterale, 8. Margo coronalis (fore limb) at the foot axis, 9. Tuber coxae, 10. Trochanter major femoris (pars caudalis), 11. Ligament collaterale geni laterale, 12. Malleolus lateralis tibiis, 13. Basis os IV metatarsale, 14. Ligament collaterale metatarsophalangi laterale, 15. Margo coronalis (hind limb) at the foot axis.

in the centre of the line of motion and recorded in order to serve as vertical and horizontal references to calibrate the analysis system. After a light warming up, horses were recorded from the right side on a 16-m-long-2-m-wide track handled at walk and trot by an experienced handler at a comfortable speed.

Then, they were placed by turns on the right side of the same vehicle with their usual team-mates. Although the positions in the vehicle were interchangeable during training, two of the horses were placed as leaders and three of them as wheelers when the study data were collected. Guided by their trainer, they were moved for some minutes in order to adapt to the new situation. After having widened the track, the calibration references were again recorded placing them in the middle of the line of motion of the horses on the right side of the vehicle and the horses were then recorded performing walk and working trot at driving.

The camera (SVHS PANASONIC ${ }^{\circledR}$, NV-M55EG, $25 \mathrm{~Hz}$ frame rate, shutter speed 1:4000) was set up perpendicularly and at $11 \mathrm{~m}$ from the middle of the line of motion. The zoom-lens, at a height of $1.2 \mathrm{~m}$, was positioned to allow a $6-\mathrm{m}$ field of view and to record 1-2 strides per trial. Six trials per horse and gait were digitised (Targa 1000 pro ${ }^{\circledR}$ digitising card) obtaining 50 fields per second. One stride per trial was analysed using a two-dimension semi-automatic analysis system (SMVD $2.03^{\circledR}$ ) by which linear, temporal and angular variables from the right fore and hind limbs were obtained. The first image with the hoof in contact with the ground without displacement in the following image (marker over the margo coronalis as reference) was taken as the starting point of the stride. The first image with the heels 
clearly off the ground was the beginning of the swing phase and the previous image the end of the stance phase.

The Speed, the time taken by the horses to travel a known distance, was the stride length divided by the stride duration and averages from the fore and hind limbs were global values for each horse. Midstance position was automatically determined by the system when the metacarpal bone was vertical for the fore limb and when the marker of the hindhoof was just under that over the hip for the hind limb according to Drevemo et al. [12], Stride durations, swing and stance phase durations were calculated with respect to the fore and hind limbs. Stride length was the difference between $x$-coordinates of the hoof markers in two consecutive contacts with the ground. Overreach distance was the difference between the $x$-coordinate of the margo coronalis of the right hind limb at the moment of the footfall and that of the fore limb at the previous placement, this being positive if the hind limb marker was ahead. Angler values from the flexor side of the joints in the fore and hind limb (Fig. 2), the inclination values of the scapula and pelvis segments with respect to the horizontal plane, and the RetractionProtraction angle of the fore limb (angle between the line joining markers over the withers and margo coronalis and the horizontal line) and the hind limb (angle between line joining markers over the hip and margo coronalis and the horizontal line) were also determined. For each of these variables the parameters analysed were the following (Tabs. I and II): maximum and minimum values throughout the stride (max and min, respectively); the difference between them (angle range of motion, ARM); angle value at the beginning of the stride (T0); at the midstance position (Midst); at the beginning of the swing phase (Lift off) and at the maximal height of the hoof (Max elev).
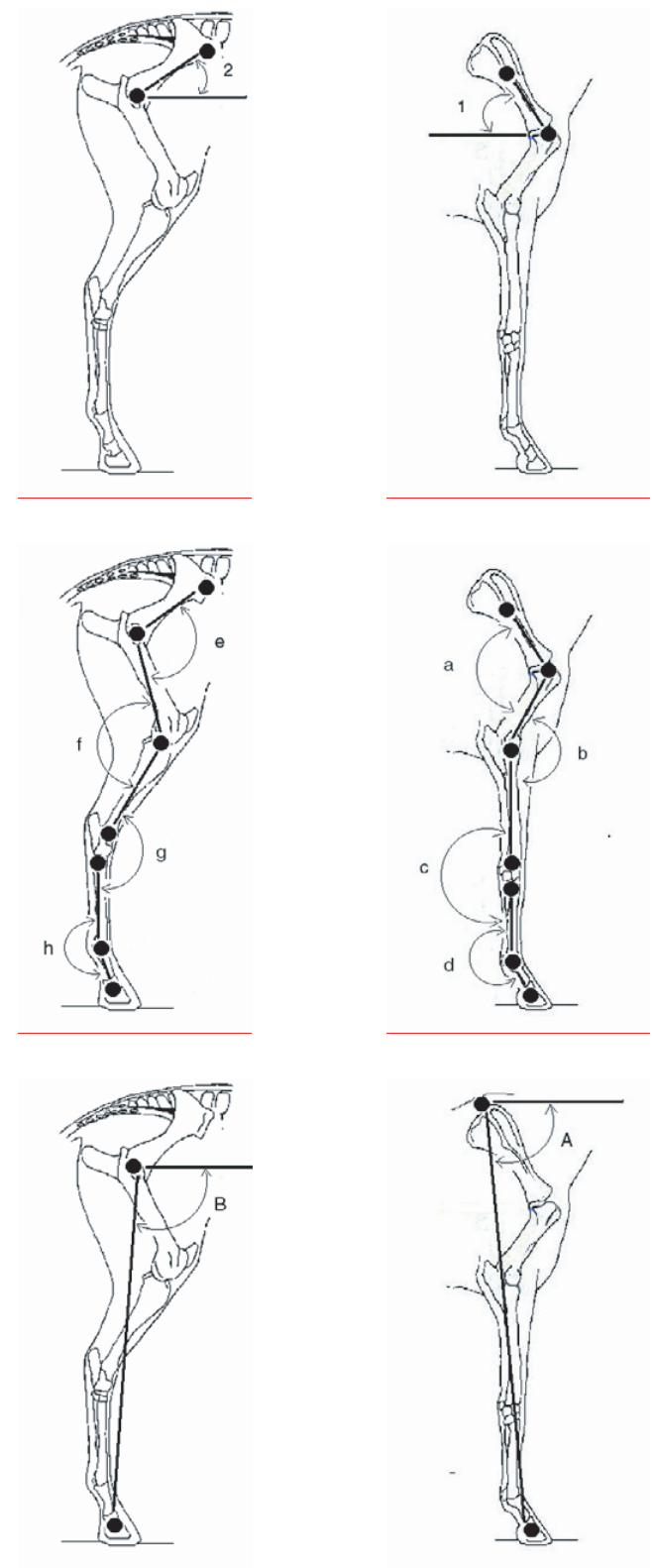

Figure 2. Schematic representation of angular variables in the fore and hind limbs: 1 . scapula inclination, 2. pelvis inclination, a. shoulder, b. elbow, c. carpus, d. fore fetlock joint, e. hip, f. stifle, g. tarsus, h. hind fetlock joint, A. Fore Retraction-Protraction angle, B. Hind Retraction-Protraction angle. 
Table I. Mean values and standard deviation for linear and temporal kinematic variables, and results of a paired Student $t$-test comparing handled and driving gaits (walk and trot) in 5 Andalusian Purebred stallions.

\begin{tabular}{|c|c|c|c|c|}
\hline & \multicolumn{2}{|c|}{ WALK } & \multicolumn{2}{|c|}{ TROT } \\
\hline & Handled & Driving & Handled & Driving \\
\hline Speed $\left(\mathrm{m} \cdot \mathrm{s}^{-1}\right)$ & $1.54 \pm 0.09$ & $1.40 \pm 0.12$ & $3.57 \pm 0.59$ & $3.12 \pm 0.40$ \\
\hline Fore stride length $(\mathrm{cm})$ & $163.1 \pm 10.8$ & $139.3 \pm 7.2 *$ & $242.2 \pm 26.4$ & $213.4 \pm 14.5 *$ \\
\hline Hind stride length (cm) & $167.5 \pm 10.2$ & $139.4 \pm 8.6 * *$ & $241.7 \pm 27.0$ & $212.3 \pm 18.6 *$ \\
\hline Overreach distance $(\mathrm{cm})$ & $8.7 \pm 14.4$ & $-13.0 \pm 8.4 * *$ & $-6.2 \pm 11.4$ & $-18.3 \pm 9.8 *$ \\
\hline Fore stride duration (s) & $1.08 \pm 0.08$ & $0.98 \pm 0.09$ & $0.69 \pm 0.03$ & $0.67 \pm 0.02$ \\
\hline Fore swing duration (s) & $0.43 \pm 0.03$ & $0.39 \pm 0.02 *$ & $0.42 \pm 0.02$ & $0.39 \pm 0.01 *$ \\
\hline Fore stance duration (s) & $0.65 \pm 0.06$ & $0.59 \pm 0.08$ & $0.27 \pm 0.02$ & $0.28 \pm 0.01$ \\
\hline Hind stride duration (s) & $1.07 \pm 0.08$ & $0.99 \pm 0.08$ & $0.69 \pm 0.03$ & $0.67 \pm 0.02$ \\
\hline Hind swing duration (s) & $0.41 \pm 0.05$ & $0.36 \pm 0.02 *$ & $0.41 \pm 0.02$ & $0.37 \pm 0.01 * *$ \\
\hline Hind stance duration (s) & $0.66 \pm 0.04$ & $0.62 \pm 0.06$ & $0.27 \pm 0.02$ & $0.29 \pm 0.02$ \\
\hline
\end{tabular}

$*, * *, * * *$ indicate statistical (significant) differences between handled and driving gaits $(P \leq 0.05$, $P \leq 0.01$ and $P \leq 0.001$, respectively).

Standard statistical methods were employed to obtain mean and standard deviation (SD) from the variables analysed in the strides selected for each horse. The means for the different gait type in individual horses were used to obtain the results in the group and a paired Student $t$-test was performed using the SAS package software (SAS Inc., 1982) in order to identify significant differences between handled and driving gaits.

\section{RESULTS}

Descriptive statistics (mean and standard deviation) for speed, as well as for temporal and linear results for handled and driving walk and trot are shown in Table I. This table also indicates which variable differs significantly between handled and driving. There were no statistically significant differences between the speed of displacement, so a further comparison was based on the Student $t$-test. When horses walked and trotted at driving, the stride length and the swing durations of both fore and hind limbs and the overreach distance decreased significantly.

The results for the angler variables of the fore limb joints, scapula inclination and fore Retraction-Protraction angle are shown in Table II. With regards to the joint values, there were more differences at trot than at walk and, although significant differences were found in the shoulder and elbow, it was the carpus and the fore fetlock which were more affected by driving conditions, mainly at trot, with both joints displaying a significantly higher ARM. With respect to the scapula inclination, the values were modified in most variables when driving and had lower ARM and maximum values. In addition, the scapula was more inclined at the midstance position.

In Table III the results (mean \pm standard deviation) for the angle values of the hind limb joints, pelvis inclination and hind Retraction-Protraction angle are shown. With regards to the angle values for the hind limb joints the stifle and tarsus were the most conditioned by driving. The stifle was more flexed at the maximum height of 
Table II. Descriptive statistic (mean \pm standard deviation) for angle values in the fore limb, and results of a paired Student $t$-test comparing handled and driving gaits (walk and trot) in 5 Andalusian Purebred stallions.

\begin{tabular}{|c|c|c|c|c|c|}
\hline & & \multicolumn{2}{|c|}{ WALK } & \multicolumn{2}{|c|}{ TROT } \\
\hline & & Handled & Driving & Handled & Driving \\
\hline \multirow{7}{*}{ Scapula incl $\left({ }^{\circ}\right)$} & $\max$ & $76.5 \pm 4.7$ & $66.5 \pm 4.0 *$ & $73.1 \pm 3.4$ & $63.2 \pm 3.7 *$ \\
\hline & $\min$ & $58.2 \pm 2.6$ & $54.1 \pm 4.4$ & $56.4 \pm 4.6$ & $49.9 \pm 5.2 *$ \\
\hline & ARM & $18.2 \pm 3.5$ & $12.4 \pm 2.4 * *$ & $16.7 \pm 2.7$ & $13.3 \pm 1.8 * *$ \\
\hline & T0 & $59.3 \pm 2.5$ & $55.0 \pm 5.0$ & $60.1 \pm 4.1$ & $53.8 \pm 4.9 *$ \\
\hline & Midst & $64.4 \pm 2.7$ & $58.3 \pm 4.3 *$ & $68.2 \pm 4.5$ & $57.1 \pm 5.4 *$ \\
\hline & Lift off & $75.6 \pm 4.1$ & $65.7 \pm 4.3 *$ & $71.8 \pm 3.5$ & $62.4 \pm 3.1 * *$ \\
\hline & Max elev & $64.2 \pm 3.1$ & $58.5 \pm 4.0 *$ & $59.7 \pm 5.7$ & $50.6 \pm 5.5 *$ \\
\hline \multirow{7}{*}{ Shoulder $\left({ }^{\circ}\right)$} & $\max$ & $124.8 \pm 4.2$ & $119.2 \pm 4.8$ & $125.8 \pm 5.9$ & $123.2 \pm 3.8$ \\
\hline & $\min$ & $114.3 \pm 4.0$ & $110.1 \pm 4.4$ & $113.0 \pm 6.1$ & $107.2 \pm 5.2$ \\
\hline & ARM & $10.5 \pm 1.8$ & $9.13 \pm 1.9$ & $12.1 \pm 2.1$ & $16.0 \pm 5.1$ \\
\hline & T0 & $123.2 \pm 5.2$ & $117.9 \pm 5.1$ & $122.7 \pm 7.4$ & $118.8 \pm 4.7$ \\
\hline & Midst & $119.2 \pm 5.2$ & $111.6 \pm 5.1 *$ & $115.5 \pm 7.6$ & $109.2 \pm 6.4$ \\
\hline & Lift off & $116.4 \pm 3.8$ & $111.1 \pm 4.7$ & $119.0 \pm 5.2$ & $113.1 \pm 5.5$ \\
\hline & Max elev & $119.2 \pm 4.5$ & $114.2 \pm 4.1$ & $117.6 \pm 5.5$ & $114.1 \pm 4.2$ \\
\hline \multirow{7}{*}{ Elbow $\left({ }^{\circ}\right)$} & $\max$ & $152.5 \pm 6.03$ & $157.0 \pm 3.0$ & $149.0 \pm 5.7$ & $156.3 \pm 4.3$ \\
\hline & $\min$ & $103.53 \pm 4.84$ & $102.3 \pm 4.5$ & $90.5 \pm 10.1$ & $85.2 \pm 9.7$ \\
\hline & ARM & $49.0 \pm 4.6$ & $54.0 \pm 2.6$ & $58.5 \pm 5.8$ & $71.1 \pm 11.4 *$ \\
\hline & T0 & $132.4 \pm 4.3$ & $135.0 \pm 2.4$ & $134.9 \pm 3.2$ & $141.5 \pm 3.0$ \\
\hline & Midst & $145.3 \pm 5.7$ & $145.9 \pm 2.8$ & $140.9 \pm 5.5$ & $146.2 \pm 4.2 *$ \\
\hline & Lift off & $144.9 \pm 8.7$ & $144.7 \pm 4.6$ & $145.0 \pm 7.5$ & 144. $0 \pm 5.1$ \\
\hline & Max elev & $109.0 \pm 5.2$ & $107.9 \pm 5.1$ & $98.0 \pm 14.8$ & $88.5 \pm 12.0$ \\
\hline \multirow{7}{*}{ Carpus $\left({ }^{\circ}\right)$} & $\max$ & $181.3 \pm 2.4$ & $184.3 \pm 1.6 *$ & $184.3 \pm 3.2$ & $185.5 \pm 2.7$ \\
\hline & $\min$ & $106.3 \pm 1.4$ & $103.8 \pm 5.8$ & $84.0 \pm 6.4$ & $80.0 \pm 7.4$ \\
\hline & ARM & $75.0 \pm 2.1$ & $80.4 \pm 5.9$ & $100.3 \pm 4.6$ & $105.5 \pm 6.3 *$ \\
\hline & T0 & $175.9 \pm 2.4$ & $176.4 \pm 2.8$ & $178.5 \pm 1.8$ & $181.0 \pm 2.0 * *$ \\
\hline & Midst & $180.5 \pm 2.8$ & $183.1 \pm 1.2 *$ & $183.5 \pm 3.3$ & $184.6 \pm 3.3$ \\
\hline & Lift off & $155.6 \pm 8.3$ & $153.8 \pm 3.4$ & $149.9 \pm 7.3$ & $144.5 \pm 5.3$ \\
\hline & Max elev & $112.2 \pm 6.1$ & $105.6 \pm 8.3$ & $86.9 \pm 4.8$ & $90.0 \pm 3.9$ \\
\hline \multirow{7}{*}{ Fore fetlock $\left({ }^{\circ}\right)$} & $\max$ & $224.4 \pm 9.8$ & $216.8 \pm 4.9$ & $240.9 \pm 10.8$ & $133.8 \pm 5.5$ \\
\hline & $\min$ & $166.4 \pm 7.7$ & $151.2 \pm 6.8$ & $150.7 \pm 4.7$ & $130.8 \pm 8.3 * *$ \\
\hline & ARM & $58.0 \pm 3.4$ & $65.7 \pm 9.9$ & $90.2 \pm 12.5$ & $103.0 \pm 12.5 * * *$ \\
\hline & T0 & $209.7 \pm 10.2$ & $195.81 \pm 3.1 *$ & $219.4 \pm 10.0$ & $205.9 \pm 4.0 *$ \\
\hline & Midst & $222.1 \pm 10.0$ & $215.1 \pm 4.4$ & $239.8 \pm 10.9$ & $232.3 \pm 4.4$ \\
\hline & Lift off & $196.7 \pm 7.9$ & $188.1 \pm 6.1$ & $187.2 \pm 2.6$ & $175.1 \pm 7.1 *$ \\
\hline & Max elev & $177.9 \pm 13.7$ & $168.3 \pm 4.9$ & $165.7 \pm 7.6$ & $143.9 \pm 14.6 *$ \\
\hline \multirow{7}{*}{ Fore retr-prot $\left({ }^{\circ}\right)$} & $\max$ & $102.9 \pm 2.9$ & $98.7 \pm 1.1$ & $99.4 \pm 3.2$ & $97.5 \pm 0.8$ \\
\hline & $\min$ & $68.1 \pm 1.3$ & $69.6 \pm 2.5$ & $64.4 \pm 3.1$ & $62.8 \pm 4.3$ \\
\hline & ARM & $34.8 \pm 3.1$ & $29.1 \pm 1.6 * *$ & $35.1 \pm 3.5$ & $34.7 \pm 4.4$ \\
\hline & T0 & $70.0 \pm 1.5$ & $72.3 \pm 2.5$ & $71.6 \pm 0.6$ & $71.9 \pm 1.8$ \\
\hline & Midst & $82.1 \pm 0.6$ & $82.2 \pm 2.7$ & $84.2 \pm 1.6$ & $82.5 \pm 2.4$ \\
\hline & Lift off & $102.8 \pm 2.8$ & $98.5 \pm 1.9$ & $99.3 \pm 3.2$ & $97.0 \pm 1.1$ \\
\hline & Max elev & $84.0 \pm 2.2$ & $83.8 \pm 3.3$ & $80.4 \pm 8.6$ & $72.0 \pm 7.5$ \\
\hline
\end{tabular}

Incl: inclination; retr-prot: retraction-protraction; max and min: maximum and minimum values throughout the stride; ARM: angle range of motion; T0: angle value at the beginning of the stride; Midst: at the midstance position; Lift off: at the beginning of the swing phase and Max elev: at the maximal height of the hoof; *, **,*** indicate statistical (significant) differences between handled and driving gaits $(P \leq 0.05, P \leq 0.01$ and $P \leq 0.001$, respectively). 
Table III. Descriptive statistics (mean \pm standard deviation) for angle variables in the hind limb, and results of a paired Student $t$-test comparing handled and driving gaits (walk and trot) in 5 Andalusian Purebred stallions.

\begin{tabular}{|c|c|c|c|c|c|}
\hline & & \multicolumn{2}{|c|}{ WALK } & \multicolumn{2}{|c|}{ TROT } \\
\hline & & Handled & Driving & Handled & Driving \\
\hline \multirow{7}{*}{ Pelvis incl $\left({ }^{\circ}\right)$} & $\max$ & $28.2 \pm 6.8$ & $28.3 \pm 3.1$ & $29.4 \pm 6.2$ & $28.4 \pm 3.2$ \\
\hline & $\min$ & $21.4 \pm 7.0$ & $23.0 \pm 2.7$ & $21.7 \pm 7.0$ & $21.6 \pm 2.5$ \\
\hline & ARM & $6.8 \pm 1.4$ & $5.2 \pm 1.5$ & $7.7 \pm 1.8$ & $6.1 \pm 1.3$ \\
\hline & T0 & $27.7 \pm 6.6$ & $27.0 \pm 3.1$ & $28.1 \pm 5.2$ & $26.5 \pm 2.7$ \\
\hline & Midst & $24.2 \pm 6.7$ & $25.8 \pm 3.9$ & $22.8 \pm 6.6$ & $22.6 \pm 2.5$ \\
\hline & Lift off & $22.4 \pm 6.6$ & $23.8 \pm 3.0$ & $23.9 \pm 6.1$ & $23.6 \pm 2.5$ \\
\hline & Max elev & $23.7 \pm 7.2$ & $26.1 \pm 3.6$ & $23.0 \pm 7.3$ & $24.5 \pm 3.1$ \\
\hline \multirow{7}{*}{$\operatorname{Hip}\left({ }^{\circ}\right)$} & $\max$ & $122.0 \pm 7.4$ & $122.0 \pm 3.7$ & $123.2 \pm 9.2$ & $123.4 \pm 4.6$ \\
\hline & $\min$ & $97.2 \pm 8.8$ & $99.0 \pm 4.7$ & $99.6 \pm 7.6$ & $99.7 \pm 2.5$ \\
\hline & ARM & $24.9 \pm 4.6$ & $23.0 \pm 2.5$ & $23.6 \pm 2.1$ & $23.7 \pm 2.7$ \\
\hline & T0 & $101.6 \pm 7.8$ & $102.0 \pm 4.1$ & $103.6 \pm 5.8$ & $103.3 \pm 2.8$ \\
\hline & Midst & $111.3 \pm 6.8$ & $113.1 \pm 3.7$ & $112.5 \pm 6.8$ & $113.0 \pm 2.8$ \\
\hline & Lift off & $120.6 \pm 7.2$ & $120.5 \pm 4.2$ & $121.7 \pm 8.9$ & $121.9 \pm 4.8$ \\
\hline & Max elev & $107.7 \pm 9.0$ & $108.1 \pm 5.0$ & $105.0 \pm 13.0$ & $105.3 \pm 4.7$ \\
\hline \multirow{7}{*}{ Stifle $\left(^{\circ}\right)$} & $\max$ & $171.7 \pm 3.6$ & $165.1 \pm 3.6$ & $167.3 \pm 4.4$ & $162.0 \pm 4.4 *$ \\
\hline & $\min$ & $135.3 \pm 3.9$ & $132.2 \pm 5.6$ & $120.7 \pm 6.4$ & $113.3 \pm 5.2 *$ \\
\hline & ARM & $36.4 \pm 6.6$ & $33.0 \pm 4.4$ & $46.6 \pm 6.4$ & $48.7 \pm 3.7$ \\
\hline & T0 & $170.0 \pm 2.4$ & $164.7 \pm 3.0 *$ & $161.1 \pm 4.7$ & $158.8 \pm 5.3$ \\
\hline & Midst & $159.7 \pm 3.6$ & $155.3 \pm 5.5$ & $156.2 \pm 1.9$ & $154.0 \pm 5.1$ \\
\hline & Lift off & $148.4 \pm 3.4$ & $145.9 \pm 5.9$ & $150.3 \pm 1.8$ & $145.2 \pm 4.4$ \\
\hline & Max elev & $139.7 \pm 5.6$ & $134.3 \pm 7.8 *$ & $132.3 \pm 6.5$ & $120.0 \pm 6.9 *$ \\
\hline \multirow{7}{*}{ Tarsus $\left(^{\circ}\right)$} & $\max$ & $166.4 \pm 2.7$ & $163.5 \pm 3.4 * *$ & $164.2 \pm 3.7$ & $160.7 \pm 2.8 * *$ \\
\hline & $\min$ & $121.7 \pm 6.3$ & $116.5 \pm 4.5 *$ & $101.0 \pm 11.1$ & $90.1 \pm 7.3 *$ \\
\hline & ARM & $44.7 \pm 5.8$ & $47.1 \pm 3.7$ & $63.2 \pm 11.6$ & $70.6 \pm 7.5$ \\
\hline & T0 & $156.6 \pm 2.5$ & $153.5 \pm 1.9 *$ & $151.6 \pm 4.6$ & $148.4 \pm 4.5 *$ \\
\hline & Midst & $155.1 \pm 3.3$ & $149.5 \pm 2.3 * *$ & $145.7 \pm 3.3$ & $142.6 \pm 3.7$ \\
\hline & Lift off & $156.8 \pm 2.4$ & $153.7 \pm 8.4$ & $158.6 \pm 3.7$ & $155.2 \pm 4.9$ \\
\hline & Max elev & $127.5 \pm 8.7$ & $117.9 \pm 5.1$ & $111.9 \pm 21.6$ & $90.6 \pm 7.5$ \\
\hline \multirow{7}{*}{ Hind fetlock $\left(^{\circ}\right)$} & $\max$ & $215.8 \pm 6.3$ & $212.6 \pm 6.0$ & $232.2 \pm 9.7$ & $230.9 \pm 6.0$ \\
\hline & $\min$ & $129.4 \pm 8.0$ & $123.4 \pm 11.0$ & $125.9 \pm 7.6$ & $120.9 \pm 8.2$ \\
\hline & ARM & $86.4 \pm 8.3$ & $89.2 \pm 11.4$ & $106.4 \pm 10.0$ & $110.0 \pm 11.25$ \\
\hline & T0 & $198.4 \pm 5.7$ & $189.2 \pm 3.4 *$ & $207.6 \pm 8.4$ & $195.7 \pm 5.4$ \\
\hline & Midst & $207.1 \pm 6.4$ & $206.9 \pm 7.2$ & $229.1 \pm 7.9$ & $224.7 \pm 6.4$ \\
\hline & Lift off & $182.0 \pm 7.3$ & $181.3 \pm 15.0$ & $176.7 \pm 8.4$ & $177.8 \pm 11.3$ \\
\hline & Max elev & $147.4 \pm 22.8$ & $143.0 \pm 17.5$ & $144.7 \pm 12.3$ & $145.2 \pm 5.9$ \\
\hline \multirow{7}{*}{ Hind retr-prot $\left({ }^{\circ}\right)$} & $\max$ & $111.9 \pm 1.2$ & $110.0 \pm 1.6$ & $112.5 \pm 3.8$ & $113.0 \pm 1.8$ \\
\hline & $\min$ & $70.9 \pm 2.5$ & $73.9 \pm 1.8 *$ & $73.9 \pm 1.5$ & $74.1 \pm 1.7$ \\
\hline & ARM & $41.0 \pm 3.6$ & $36.0 \pm 2.2 *$ & $38.6 \pm 3.3$ & $38.9 \pm 2.3$ \\
\hline & T0 & $71.2 \pm 2.2$ & $74.6 \pm 2.3 * *$ & $76.2 \pm 1.3$ & $77.6 \pm 2.3$ \\
\hline & Midst & $89.9 \pm 0.2$ & $89.9 \pm 0.1$ & $89.9 \pm 0.2$ & $90.0 \pm 0.2$ \\
\hline & Lift off & $111.7 \pm 1.2$ & $109.6 \pm 1.5$ & $111.0 \pm 3.5$ & $112.2 \pm 1.4$ \\
\hline & Max elev & $94.5 \pm 10.5$ & $91.6 \pm 5.6$ & $91.0 \pm 15.0$ & $87.0 \pm 4.9$ \\
\hline
\end{tabular}

Incl: inclination; retr-prot: retraction-protraction; max and min: maximum and minimum values throughout the stride; ARM: angle range of motion; T0: angle value at the beginning of the stride; Midst: at the midstance position; Lift off: at the beginning of the swing phase and Max elev: at the maximal height of the hoof; *, **, *** indicate statistical (significant) differences between handled and driving gaits $(P \leq 0.05, P \leq 0.01$ and $P \leq 0.001$, respectively). 
the hoof while driving at walk and trot, and the tarsus modified the maximum and minimum values in both driving gaits. In addition, the Retraction-Protraction angle was modified by the use of the vehicle only at walk.

\section{DISCUSSION}

In the present study, the horses were led at hand at a similarly comfortable speed to those reported for handled walk and trot in other kinematic studies in Andalusian horses by Galisteo et al. [14,15]. The speed for walk and trot at driving was selected by the driver in order to display the correct gaits as is usual in competition. The four horses must act as a team and, according to the FEI regulations [13], "perform a regular unconstrained walk of moderate length, the horse remaining in a light contact, walking energetically but calmly, with even and determined steps and a forward, active working trot with the horse on the bit, carrying himself in balance and rhythm with even, elastic steps and good hock action".

It might be supposed that driving acts against movement and overloads joint functions. Other kinematic studies have proved this in different situations. It has been commonly suggested that mounted horses tend to shorten their suspension phase at trot. This was observed by Sloet et al. [25] in mounted and lead-loaded horses by analysing the relative duration of the stance phase. After the present study, the same might be assumed in driving horses at walk and working trot because fore and hind swing duration phases were significantly lower under driving conditions compared to the handled gaits (Tab. I).

In the present study, the stride durations in both fore and hind limbs at walk and trot did not differ between handled and driving situations. These results were in accordance with the findings of Sloet et al. [25] who reported no differences in stride durations between non loaded, mounted and lead-loaded horses. It could be imagined that, at fixed speeds, driving horses try to maintain the stride duration of their natural gaits.

The stride length covered at a known speed and the overreach distance give an idea of the effectiveness of the movement and both are modified if the horse cannot display its natural balance. Clayton [11] found that an added weight condition in jumping horses caused the fore limbs to land closer to the fence, the difference being significant for the leading fore limb. In this study, the stride length and the overreach distance were significantly lower when horses were at driving compared to handled walk and trot. The decrease in these two distances may be related to the shortening of the swing phase. The opposite force exerted by the carriage and driver's weight counteract the impulse of the horse's movement decreasing the swing period of both fore and hind limbs and, consequently, the stride length covered at the same approached speed. These findings were not in accordance with Gottlieb et al. [16] who found that the stride length was constant throughout incremental draught work on a treadmill at a $5 \mathrm{~m} \cdot \mathrm{s}^{-1}$ speed considering that at a slow trotting stride the length seems to be determined by the speed regardless of increasing weight resistance.

The FEI rules [13] indicate that for a driving walk the hindfeet must touch the ground in front of the foot prints of the fore feet, and that for a working trot the steps of the hindfeet must at least touch the ground in the footprints of the fore feet. The Andalusian horses failed to fulfil these rules since they placed the hindhooves behind the corresponding fore feet although the driver's subjective impression was that the horses had moved correctly. The results concerning the linear, temporal and angular measurements of walk and 
trot were similar to those presented in other studies of the same breed by Galisteo et al. $[15,16]$.

According to most riders a sloping scapula facilitates freedom of movement in the fore limbs. Holmström et al. [18] studied the conformational characteristics of elite sport horses and found that elite dressage horses had more sloping shoulders and Holmström and Philipson [19] showed a positive correlation between good gaits and sloping shoulders in warm blood horses. It could then be thought that the inclination of this region with respect to the horizontal plane influences the quality of movement in the fore limb. With regards to functional characteristics, the results of the present study have shown this variable as one of those most affected by driving conditions in their values at some moments of the stride, in their minimum and maximum values and, consequently, in their range of motion. It might be supposed that during locomotion the proximal part of the fore limb is very important for the adaptation of natural gaits to new situations. Holmström et al. [22] found that, having the trot at hand as a reference, the maximum scapula inclination value diminished in relation to the collected gaits studied, the elbow and carpal joints being only slightly modified. Andalusian horses at a driving walk had a lower range of motion of the Retraction-Protraction angle, but the range of motion of this variable was not modified in the trotting horses although the stride length was significantly lesser in the driving trot. The fact that a larger number of joint variables changed their values at trot might explain the maintenance of the range of motion in the RetractionProtraction angle and the decrease in the stride length. The finding that shoulder and elbow values between handled and driving horses showed scarcely significant differences might reflect that these two joints have little influence on adaptation to driving conditions. The maximum value of the carpus was higher and this joint was more extended at the midstance position at walk while driving, perhaps as a consequence of the increase in the impulse during the stance phase. Horses at driving displayed an increase in their range of motion in the carpus, elbow, and fetlock joints but only significantly increased at driving trot compared to the handled one. Significant increases in maximal fore fetlock extension have been observed in walking and trotting horses loaded with $90 \mathrm{~kg}$ in weight by Sloet.et al. [25], who found that a rider and lead loading the same weight increased the fetlock extension in horses comparably in the fore limb at walk. Clayton [11] reported that an addition of $18 \mathrm{~kg}$ extra weight in jumping horses increased the extension of the fore fetlock and carpal joint at landing in the leading but not in the trailing fore limb. Back et al. [1,5] pointed out the fetlock extension as an indication of the magnitude of the ground reaction force. Cano et al. [7] found the greatest differences for the fore limb variables between young and adult Andalusian horses at trot displayed by the most distal segment, referring to the carpal and fetlock joints. In the present study, significant increases in the range of motion of the fore fetlock joints were found at the driving trot and this was due to a higher flexion during the swing phase. Although there was an increase in the range of motion and a lower minimum value of this joint at the driving walk with respect to the handled one, the statistic analysis did not show any significant differences and the results suggest that, although the function of the fore fetlock joint is affected by driving, there is probably no significant increase in vertical force to cause changes in maximal extension.

Holmström et al. [2] and Back et al. [6] found that the stifle and the tarsal joints are part of the system for storage of elastic strain and propulsion in addition to the pelvis and hind fetlock joints. In the 
hind limbs, a small minimum angle of the tarsal joint and low minimum of the Retraction-Protraction angle have been described as an indicator of a good trot by Back et al. [3], and Holmström et al. [20] suggested a smaller minimum angle of tarsal and fetlock joints as being a positive characteristic. With regards to the angular variables of the hind limb in the present study, the stifle, the tarsus and the Retraction-Protraction angles were those most modified with driving. Differences were found both at walk and trot in the stifle at the moment of the maximum height of the hooves, where it was more flexed in driving horses.

The minimum and maximum values of the tarsus of Andalusian horses analysed in the present study were significantly modified when driving at working trot. The tarsus did not extend in the driving trot as much as in the handled trot and the flexion values were higher at driving conditions. All the above may indicate that although the angle range of motion of the stifle and tarsus may not be influenced by the fact of pulling the carriage, the maximum and minimum values of these joints at trot could be altered under driving conditions.

Some situations have proven to cause modifications from the kinematic pattern of joint variables in the hind limbs. The effects of a rider or a lead load of the same weight on the hind limb function found by Sloet et al. [25] were increases both in the maximal fetlock range of motion and the maximal fetlock extension at walk and trot, which were smaller than those in the fore limbs and only significant at trot. No significant differences in the maximum, minimum and ARM of the stifle joint were found between the driving horses and the handled ones at walk in the present study, although the variables tended to be slightly different. However, both maximum and minimum values of the same joint were modified with driving conditions at trot.
The engagement of the hind limbs in horses has been commonly sought by riders. Back et al. [3] pointed out the hind limb protraction as a kinematic variable indicative of gait quality and predictive of the locomotor performance of the mature horse. The fact that in the present study with regards to the Retraction-Protraction angle there was less ARM in the driving walk than in the handled one and that the capacity of protraction (minimum value) decreased might indicate that horses at driving step under themselves less than in a handled walk. However, the results of the trot led to the idea that there is no change in the engagement values from handguided to driving gaits at the selected speeds. These results could be used for the prediction of some desirable kinematic parameters for sporting purposes.

In conclusion, the walk and working trot at driving modify the natural kinematics of horses. Being under driving conditions counteracts the impulse, decreasing the swing period and, consequently, the stride length of both fore and hind limbs and the overreach distance. The scapular function at walk and trot, the fore fetlock values at trot and stifle and tarsus parameters were those most modified with the driving conditions. The stride durations at walk and trot and Retraction-Protraction values in the hind limbs at trot did not differ from handled to driving gaits. It may be supposed that at fixed speeds driving horses try to maintain the stride duration of their natural gaits.

\section{ACKNOWLEDGEMENTS}

The authors thank the staff of the 3rd Military Stud Farm (Ecija, Seville, Spain) and trainer-driver Mr. Juan Robles for helping with the data collection.

\section{REFERENCES}

[1] Back W., Barneveld A., van Weeren P.R., van den Bogert A.J., Kinematic gait analysis 
in equine carpal lameness, Acta Anat. 146 (1993) 86-89.

[2] Back W., van den Bogert A.J., van Weeren P.R., Bruin G., Barneveld A., Quantification of the locomotion of Dutch Warmblood foals, Acta Anat. 146 (1993) 141-147.

[3] Back W., Barneveld A., Bruin G., Schamhardt H.C., Hartman W., Kinematic detection of superior gait quality in young trotting Warmbloods, Vet. Quart. (Suppl. 2) (1994) 91-96.

[4] Back W., Barneveld A., Schamhardt H.C., Bruin G., Hartman W., Longitudinal development of the kinematics of 4-, 10-, 18-, and 26-month-old Dutch Warmblood horses, Equine Vet. J. (Suppl. 17) (1994) 3-6.

[5] Back W., Schamhardt H.C., Savelberg H.H., van den Bogert A.J., Bruin G., Hartman W., Barneveld A., How the horses moves 1: Significance of graphical representations of equine fore limb kinematics, Equine Vet. J. 27 (1995) 31-38.

[6] Back W., Schamhardt H.C., Savelberg H.H., van den Bogert A.J., Bruin G., Hartman W., Barneveld A., How the horse moves 2: Significance of graphical representations of equine hind limb kinematics, Equine Vet. J. 27 (1995) 39-45.

[7] Cano M.R., Miró F., Vivo J., Galisteo A.M., Comparative biokinematic study of young and adult Andalusian horses at the trot, J. Vet. Med. A. 46 (1999) 91-101.

[8] Cano M.R., Miró F., Monterde J.G., Diz A., Martin J., Galisteo A.M., Changes due to age in the kinematics of trotting Andalusian foals, Equine Vet. J. (Suppl. 33) (2001) 116121.

[9] Clayton H.M., Comparison of the stride kinematics of the collected, working, medium and extended trot in horses, Equine Vet. J. 26 (1994) 230-234.

[10] Clayton H.M., Comparison of the stride kinematics of the collected, medium and extended walks in horses, Am. J. Vet. Res. 56 (1995) 849-852.

[11] Clayton H.M., Effects of added weight on landing kinematics in jumping horses, Equine Vet. J. (Suppl. 23) (1997) 50-53.

[12] Drevemo S., Dalin G., Fredicson J., Hjertén G., Equine locomotion 1: The analysis of linear and temporal stride characteristics of trotting Standardbreds, Equine Vet. J. 12 (1980) 60-65.

[13] FEI (Fédération Équestre Internationale), Rules for Driving Events, 9th ed., 2005.

[14] Galisteo A.M., Cano M.R., Miró F., Vivo J., Morales J.L., Agüera E., Angular joint pa- rameters in the Andalusian horse at walk, obtained by normal videography, J. Equine Vet. Sci. 16 (1996) 73-77.

[15] Galisteo A.M., Vivo J., Cano M.R., Morales J.L., Miró F., Agüera E., Differences between Breeds (Dutch Warmblood vs. Andalusian Purebred) in Fore limbs kinematics, J. Equine Sci. 8 (1997) 43-47.

[16] Gottlieb M., Essen Gustavsson B. Lindoholm A., Persson S.G.B., Circulatory and muscle metabolic responses to draught work compared to increasing trotting velocities, Equine Vet. J. 20 (1988) 430-434.

[17] Grant B.D., Performance prediction, Equine Athlete 2 (1989) 1-2.

[18] Holmström M., Magnusson L.E., Philipsson J., Variation in conformation of Swedish warmblood horses and conformational characteristics of elite sport horses, Equine Vet. J. 22 (1990) 186-193.

[19] Holmström M., Philipson J., Relationships between conformation, performance and health in 4-year-old Swedish warmblood riding horses, Livest. Prod. Sci. 33 (1993) 293 312.

[20] Holmström M., Fredicson I., Drevemo S., Biokinematic analysis of the Swedish Warmblood riding horse at trot, Equine Vet. J. 26 (1994) 235-240.

[21] Holmström M., Fredicson I., Drevemo S., Biokinematic differences between riding horses judged as good and poor at the trot, Equine Vet. J. (Suppl. 17) (1994) 51-56.

[22] Holmström M., Fredicson I., Drevemo S., Biokinematic effects of collection on the trotting gaits in the élite dressage horse, Equine Vet. J. 27 (1995) 281-287.

[23] Miró F., Morales J.L., García-Palma G., Galisteo A.M., Collection in the passage and piaffe of Spanish Purebred horse. A preliminary report, Pferdeheilkunde 12 (1996) 693697.

[24] Pérez R., Valenzuela S., Merino V., Cabezas I., García M., Bou R., Ortiz P., Energetic requirements and physiological adaptations of draught horses to ploughing work, Anim. Sci. 63 (1996) 343-351.

[25] Sloet van Oldruitenborgh-Oosterbaan M.M., Barneveld A., Schamhardt H.C., Effects of weight and riding on workload and locomotion during treadmill exercise, Equine Vet. J. (Suppl. 18) (1995) 413-417.

[26] Snow D.H., Haematological, biochemical and physiological changes in horses and ponies during the cross country stage of driving trial competitions, Vet. Rec. 10 (1990) 233-239. 